\title{
Erratum to: Amyloidogenic $\alpha$-synuclein seeds do not invariably induce rapid, widespread pathology in mice
}

\author{
Amanda N. Sacino • Mieu Brooks • Michael A. Thomas • Alex B. McKinney • \\ Nicholas H. McGarvey $\cdot$ Nicola J. Rutherford · Carolina Ceballos-Diaz • \\ Janice Robertson · Todd E. Golde · Benoit I. Giasson
}

Published online: 9 October 2014

(C) Springer-Verlag Berlin Heidelberg 2014

\section{Erratum to: Acta Neuropathol (2014) 127:645-665 \\ DOI 10.1007/s00401-014-1268-0}

In our original paper, the rows of images in Fig. $1 \mathrm{~b}$ were inverted and the bottom right (pSer129 stained) image was from the hypothalamic region and not the brainstem region as indicated in the figure legend. We have now correctly rearranged the rows of images to correspond with the text in the figure. We have also replaced the pSer129 immunostained image from the symptomatic, aging M83 mouse to reflect a region in the brainstem as indicated in the original legend.

The online version of the original article can be found under doi:10.1007/s00401-014-1268-0.

A. N. Sacino - M. Brooks - M. A. Thomas - A. B. McKinney ·

N. H. McGarvey · N. J. Rutherford · C. Ceballos-Diaz ·

T. E. Golde $(\bowtie) \cdot$ B. I. Giasson $(\bowtie)$

Department of Neuroscience, Center for Translational Research

in Neurodegenerative Disease, and McKnight Brain Institute,

College of Medicine University of Florida, Gainesville,

FL 32610, USA

e-mail: tgolde@ufl.edu

B. I. Giasson

e-mail: bgiasson@ufl.edu

J. Robertson

Department of Laboratory Medicine and Pathobiology, Tanz

Centre for Research in Neurodegenerative Diseases, University

of Toronto, Toronto, ON M5S 3H2, Canada 
a $\bullet$ aS pathology in symptomatic M83 $\bullet$ Additional $\alpha$ S pathology induced post-injection
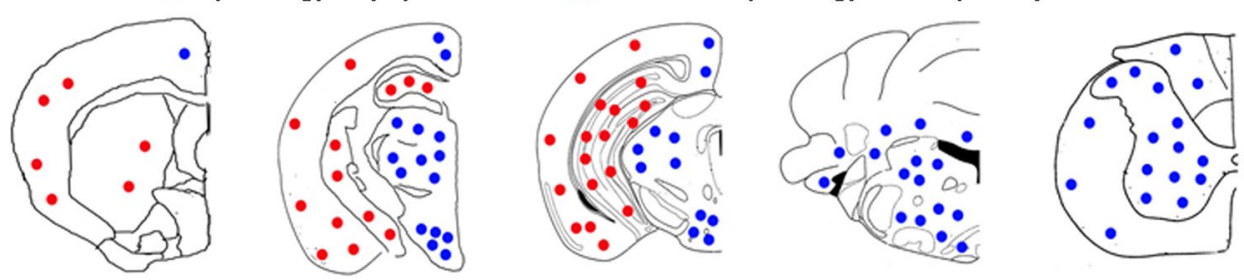

b

pSer129

Syn506

p62

\section{Symptomatic M83 15M}

hfib $\alpha \mathrm{S}$

M83 2M

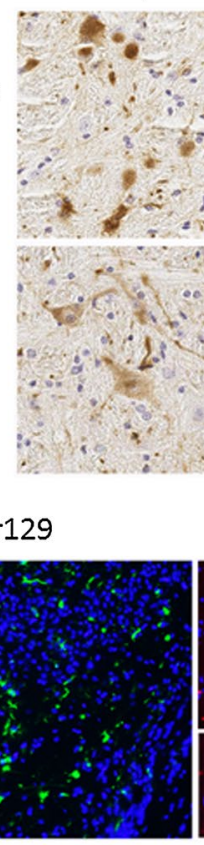

\section{9}

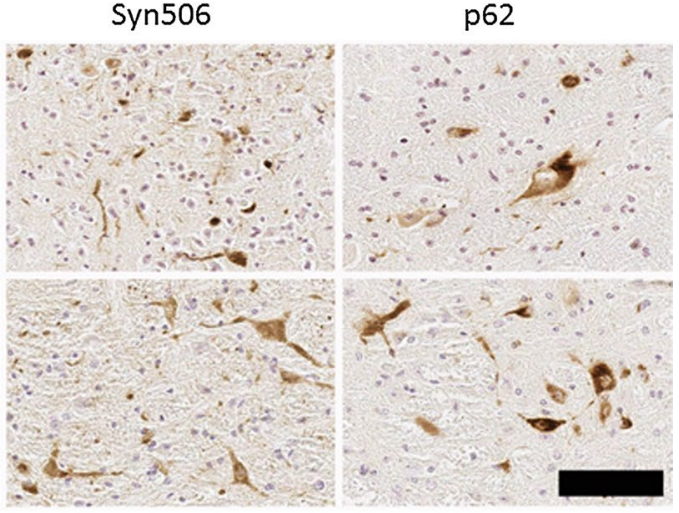

c

pSer129

SNL-4

Merge
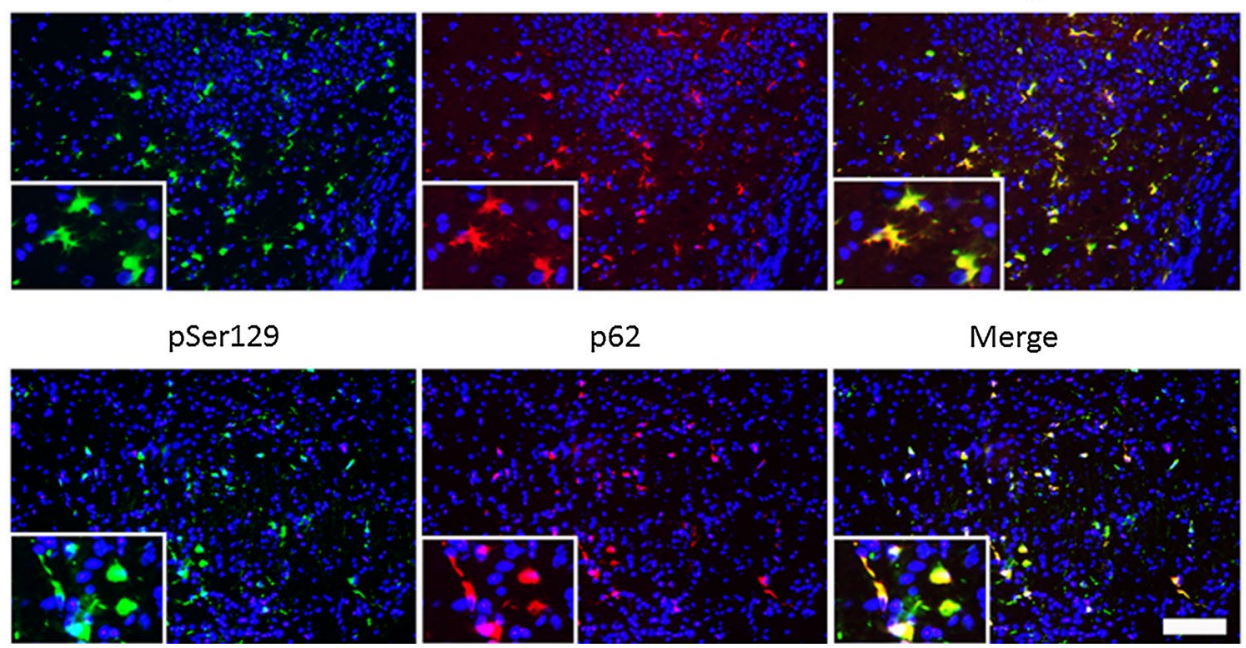

p62

Merge

Fig. 1 Induction of $\alpha \mathrm{S}$ pathology at 2 months post-intrahippocampal injection of 21-140 hfib $\alpha \mathrm{S}$ in M83 Tg mice. a Schematic map showing rostral-caudal distribution of $\alpha \mathrm{S}$ pathology in M83 Tg mice following hippocampal injection of 21-140 hfib $\alpha \mathrm{S}$. In these mice there was robust induction of $\alpha \mathrm{S}$ pathology at the site of injection, but also throughout the CNS. Blue dots indicate locations of intrinsic $\alpha \mathrm{S}$ pathology observed when M83 Tg mice become symptomatic with aging [33] and red dots indicate locations of additional $\alpha \mathrm{S}$ pathology uniquely induced by hippocampus injection with 21-140 $\mathrm{hfib} \alpha \mathrm{S}$. Therefore, in M83 Tg mice injected with 21-140 hfib $\alpha \mathrm{S}, \alpha \mathrm{S}$ neuronal inclusions were observed in the location indicated by both red and blue dots. Similar density and distribution of $\alpha \mathrm{S}$ pathology was seen bilaterally. This distribution of $\alpha \mathrm{S}$ inclusions was assessed with both pSer129/81A and Syn506 antibodies. b IHC of brainstem tissue sections from a symptomatic 15-month-old M83 Tg mouse and a M83 Tg mouse at 2 months post-intrahippocampal injection of 21-140 hfib $\alpha \mathrm{S}$ showing pSer129/81A + inclusions that fill the cell bodies and extend out into the processes along with the presence of dystrophic neurites. These $\alpha \mathrm{S}$ inclusions are also readily detected by staining with Syn506 and p62 antibodies. Tissue sections were counterstained with hematoxylin. c Double immunofluorescence analysis of the hippocampal region of a M83 $\mathrm{Tg}$ mouse at 2 months postintrahippocampal injection of 21-140 hfib $\alpha \mathrm{S}$ for pSer129 (green) and SNL-4 (red; upper panels) or p62 (red; lower panels) shows that all pSer129/81A+ perikaryal inclusions are also SNL-4+ and that the majority of pSer129/81A+ inclusions are also p62+. Cell nuclei were counterstained with DAPI. Scale bar 100 and $25 \mu \mathrm{m}$ (inset) 